\title{
PENGARUH INOVASI TIM TERHADAP KINERJA TIM DENGAN BUDAYA TIM SEBAGAI VARIABEL MODERASI \\ DI KOPINKRA SATYA BHAWANA KASONGAN, KABUPATEN BANTUL
}

\author{
Dody Rahmat Sholihin ${ }^{1}$
}

\begin{abstract}
This study aims to analyze the relationship of team innovation on team performance in ceramic potter teams and analyze the influence of team culture as a moderating variable in relation to team innovation on team performance in Cooperative Industrial Ceramics (Kopinkra) Satya Bhawana in Bantul, Yogyakarta. The used Testing in this study was linear regression and interaction test (MRA). The results of this study include, among others: first, team innovation have significant positive effect on team performance in Kopinkra Satya Bhawana. Effect of team innovation on team performance is 2,137 with a significant level of to 0,000. This condition is caused by some progressive craftsmen that produce objects which have the advantages of modern decorative material capital, symbolic and cultural. Second, the effect was not significant in the team culture moderate the relationship team innovation on team performance. Coefficient of moderation in influencing the performance of the team in Kopinkra Satya Bhawana is 0.001 with a significance level of 0.982. The reason is the process of coordinating the team as part of a team culture that carried the team in Kopinkra Satya Bhawana potter not in balance.
\end{abstract}

Keywords: Team Innovation, Team Performance, Team Culture, Cooperative

\section{ABSTRAK}

Penelitian ini menganalisa hubungan inovasi tim terhadap kinerja tim pada tim gerabah serta menganalisa pengaruh budaya tim sebagai variabel moderasi pada hubungan inovasi tim terhadap kinerja tim perajin gerabah di Kopinkra Satya Bhawana (Kopinkra) di Bantul, Yogyakarta. Pengujian penelitian ini menggunakan regresilinear dan uji interaksi. Hasil penelitian ini di antaranya meliputi: pertama, inovasi tim berpengaruh positif dan signifikan terhadap kinerja tim pada tim perajin gerabah Kopinkra Satya Bhawana. Pengaruh inovasi tim terhadap kinerja tim sebesar 2,137 dengan tingkat signifikan 0,000. Kondisi ini disebabkan adanya beberapa pengrajin progresif yang memproduksi benda hias modern dengan keunggulan modal materi, simbolik dan budaya. Kedua, budaya tim (kekompakan tim, koordinasi tim dan dukungan tim) ternyata tidak ada korelasi dan pengaruhnya tidak signifikan dalam memoderasi hubungan inovasi tim dengan kinerja tim perajin gerabahdi Kopinkra Satya Bhawana. Nilai koefisien moderasi dalam mempengaruhi kinerja tim sebesar 0,001 dengan tingkat signifikansi 0,982. Kondisi ini disebabkan adanya proses koordinasi tim sebagai bagian dari budaya tim yang dijalankan tim perajingerabah tidak berjalan seimbang.

Kata kunci: Inovasi Tim, Kinerja Tim, Budaya Tim, Koperasi

\footnotetext{
${ }^{1}$ Dosen, STIA “AAN” Yogyakarta , email: dodyrahmatsholihin88@gmail.com
} 


\section{PENDAHULUAN}

Dalam menghadapi era pasar bebas, tim berkinerja tinggi dalam perkembangan industri menjadi poin penting yang menentukan. Tidak terkecuali pula pada perajin gerabah yang harus terus berbenah mengikuti perkembangan zaman. Produsen gerabah kini harus mampu bekerja secara tim untuk menjaga, mendapatkan konsumen dan merespon tuntutan pasar yang bervariasi(Doolen, et,al, 2003; Wilson, et,al, 2007; Pryor, et,al, 2009; Fransen, et,al, 2011). Anggota tim diharapkan dapat memberi ide-ide inovatifnya (inovasi tim) dalam rangka menyediakan produk dan layanan baru yang lebih kreatif (Mathieu, et. al, 2008). Kondisi ini tidak terlepas dari karakteristik tim sebagai berkumpulnya dua individu atau lebih yang saling berinteraksi, memiliki tujuan bersama, memiliki peran dan tanggung jawab yang berbeda, saling ketergantungan antara tujuan, cara dan hasil; serta bersama-sama dalam sebuah sistem organisasi dan lingkungan (Kozlowski dan Ilgen, 2006).

Kebaruan dalam penelitian ini adalah studi ini menyoroti kemampuan inovasi tim dalam menstimulus kinerja tim pada tim perajin gerabah. Penelitian di bidang ini masih terbatas, khususnya pada level koperasi Usaha Kecil dan
Menengah (Matthing, et. al, 2004; Zsuzsanna, et. al, 2014). Kinerja tim didefinisikan sebagai sejauh mana tim dapat menyelesaikan tujuan atau misinya (Devine dan Philips, 2001). Menurut Stashevsky dan Koslowsky (2006), kinerja tim adalah fungsi dari tingkat pengetahuan dan kekompakan tim. Kinerja tim merupakan serangkaian proses organisasi untuk mengelola implementasi strategi, mengkomunikasikan posisi dan kemajuan, dan mempengaruhi perilaku dan tindakan karyawan (Franco-Santos, et. al, 2007). Baruch dan Lin (2012) mendefinisikan kinerja tim sebagai proses tim menyelesaikan tujuan atau misi, saling berbagi pengetahuan, informasi atau pengalaman organisatoris yang relevan, meningkatkan sumber daya tim dan mengurangi waktu terbuang dalam proses uji coba atau kontrol kualitas. Beberapa karakteristik mendasar kinerja tim yang efektif diantaranya meliputi: anggota tim berhasil mengintegrasikan tindakan masing-masing, tim semakin dibutuhkan untuk tampil di lingkungan yang kompleks dan dinamis, dan anggota tim harus bekerja lebih adaptif ketika mengkoordinasikan tindakannya (Zaccaro, et. al, 2001; Zaccaro dan Klimoski, 2002). Pada studi ini, kinerja 
tim dilihat sebagai hasil bekerja tim dalam mencapai tujuannya. Inovasi tim merupakan respons tim terhadap kompleksnya situasi dalam menghadapi perubahan teknologi, globalisasi, kompetisi, dan peningkatan kegiatan ekonomi berbasis pengetahuan (Kozlowski dan Bell, 2008; Baker dan Sinkula, 2002; Darroch dan McNaughton, 2002). Inovasi tim merupakan fenomena yang berbeda dari individu. Inovasi tim berasal dari kesadaran yang mempengaruhi perilaku atau karakteristik lain dari individuindividu, diperkuat oleh interaksi mereka, dan bermanifestasi menjadi fenomena kolektif dalam tim (Kozlowski dan Klein dalam Reiter-Palman et. al, 2012). Secara proses, anggota tim dapat menghasilkan ide-ide kreatif dan kritis untuk diolah, membuang ide-ide yang tidak berguna dan menerapkan ide-ide yang berguna (Amabile, et. al, 1996). Beberapa manfaat inovasi tim di antaranya meliputi: memberikan keunggulan kompetitif jangka panjang yang unggul pada tim (Fichman, 2001; Martins dan Terblanche, 2003; Wong dan Chin, 2007; Bate, 2010; Naranjo-Valencia, et,al, 2011), menawarkan kinerja pelayanan terbaru (Santos-Vijande, 2012), perubahan strategi inovasi layanan (Lightfoot dan Gebauer, 2011), perubahan lingkungan kerja yang menyenangkan dan mengarah pada peningkatan inovasi anggota (Huhtala dan Parzefall, 2007) serta berguna bagi perkembangan individu, tim, organisasi, atau masyarakat luas (Somech dan Drach-Zahavy, 2001; 2013).

Offenbeek dan Koopman (dalam Drach-Zahavy dan Somech, 2001) mengemukakan empat proses interaksi dalam inovasi tim di antaranya meliputi: proses pertukaran informasi, pembelajaran, memotivasi, dan negosiasi. Sedangkan West (dalam Drach-Zahavy dan Somech, 2001) memaparkan empat fase inovasi tim di antaranya meliputi: pengakuan kesempatan untuk inovasi, awal proses tim untuk mendorong implementasi, implementasi inovasi, dan stabilisasi inovasi. Peleckis (2014) memaparkan beberapa fase inovasi tim di antaranya adalah fiksasi pelacakan masalah atau identifikasi kebutuhan, persiapan, inkubasi (suspensi), deskripsi ide secara sistematis, mencari solusi dan evaluasi. Penelitian ini menempatkan inovasi tim sebagai proses rekayasa internal dan eksternal oleh tim dalam memahami peluang dan tantangan perubahan lingkungan bagi kemajuan tim dan organisasi.

Beberapa literatur mengkaji variabel yang mempengaruhi kinerja organisasi industri keramik. Misalnya: kerja sama, kapasitas adaptasi, kapasitas 
swadana, pengembalian modal, tingkat sumbangan teknis, biaya personil tiap karyawan dan investasi tiap karyawan (Jackson dan Tomlinson, 2009; HervasOliver, et,al, 2011; Tomlinson dan Jackson, 2011; Zsuzsanna dan Marian, 2012). Sedangkan pada sisi lainnya, teoriteori inovasi tim saat ini lebih banyak meneliti variabel yang mempengaruhi inovasi tim dibandingkan dengan praktik inovasi tim itu sendiri dan khususnya belum ada mengkaji pada tim perajin gerabah/keramik (Amabile et,al, 1996; Keller, 2001; Bain, et,al, 2001;Bandow, 2001; Chansler, et,al, 2003;Costa, 2003; Pryor, et,al, 2009; Hulsheger, et,al, 2009; Rosing, et,al, 2011; Reiter-Palman et,al, 2012; Heller, et,al, 2014). Di samping itu, studiini menempatkan budaya tim sebagai variabel moderasi pada hubungan inovasi tim terhadap kinerja tim.Tim diduga memiliki aturan, harapan, dan peran bersama di dalam tim sehingga budaya tim dapat muncul. Budaya tim merupakan himpunan nilai-nilai umum yang diterima tim dalam melakukan sesuatu sehingga terbentuk "cara bersama" yang meresap di antara para anggota tim (Shim, 2010; García-Herrero, et,al, 2013). Budaya tim memungkinkan anggota tim dapat berbagi, berdialog konstruktif dan mengimplementasikan ide-ide mereka. Sementara itu, anggota tim tetap dapat mempertahankan ruang privasinya untuk berinovasi. Adapun alasan mengapa budaya tim dijadikan variabel moderasi karena eksisnya budaya tim diduga dapat memperkuat atau memperlemah hubungan inovasi tim terhadap kinerja tim (Hu, et,al, 2009). Pada sisi lainnya, hasil pengukuran moderasi budaya tim ini dapat saja bertentangan dan tidak meyakinkan karena ide yang tidak disaring atau hanya melalui satu atau dua anggota tim (Leenders, et,al, 2003; Chen et,al, 2007).

Objek penelitian yang dikaji adalah tim perajin gerabah pada Koperasi perajin keramik (Kopinkra) Satya Bhawana di desa Kasongan, Bangunjiwo, Kasihan, Bantul, Yogyakarta. Koperasi tersebut telah mengelola sejumlah 370 tim perajin gerabah dengan jumlah karyawan 2.500 orang. Pada sisi inovasi, setiap tim memiliki kreatifitas produk sendiri, baik modern dan tradisional seperti: disain struktural dan ornamental bentuk, bahan, teknologi garap, fungsi, dan hiasan.Pada tiap tim, sejumlah karyawan yang memiliki tugas masing-masing, komitmen dan saling ketergantungan dalam mencapai target bersama. Kondisi tersebut diperkuat dengan ketrampilan membuat gerabah yang diwariskan dari generasi-generasi sebelumnya. Dampaknya, prestasi Kopinkra Satya Bhawana yang diraih saat ini adalah sebagai proyek percontohan One Village 
One Product (OVOP) nasional dan penggerak OVOP terbaik tingkat nasional dari Kementerian Koperasi UMKM pada tahun 2013.

Namun, realitanya saat ini terjadi sejumlah permasalahan. Secara kumulatif, terjadi penurunan produktifitas jumlah ekspor, khususnya Eropa. Selama tahun 2014, para perajin hanya bisa mengirim paling banyak 70 kontainer per bulan. Sebelumnya, diketahui bahwa perajin gerabah di Kasongan sempat mengalami kenaikan ekspor pada tahun 2007-2008 dengan rata-rata ekpor produk 130 kontainer per bulan dengan nilai antara 75-100 juta/kontaine. Disamping itu, masih terdapat perajin Kopinkra Satya Bhawana yang memiliki sejumlah masalah.Salah satunya adalah Mrajak. Perajin tersebut memiliki kesulitan dalam hal permodalan, keterbatasan atau tidak luasnya tempat usaha, keterbatasan jumlah dan keahlian perajin serta pengelolaan keuangan belum profesional. Kondisi tersebut memberi sinyalemen bahwa tidak semua tim perajin gerabah di Kopinkra Satya Bhawana memiliki kinerja tim yang baik.

Tujuan studi ini adalah menganalisa hubungan antara inovasi tim dan kinerja tim pada tim perajin gerabah di Kopinkra Satya Bhawana serta mengetahui apakah budaya tim memoderasi hubungan antara inovasi tim dan kinerja tim perajin gerabah di Kopinkra Satya Bhawana. Budaya tim dijadikan sebagai variabel moderasi terhadap kedua variabel. Budaya tim diekspektasikan dapat memperkuat atau memperlemah pengaruh inovasi tim terhadap kinerja tim perajin gerabah di Kopinkra Satya Bhawana. Adanya proses implementasi inovasi diharapkan berkontribusi terhadap pencapaian keunggulan kompetitif yang unggul (Baker dan Sinkula, 2002; Darroch dan McNaughton, 2002; Santos-Vijande, 2012). Penelitian ini mengusulkan bahwa inovasi tim secara kolektif memiliki nilai positif terhadap kinerja tim. Kondisi ini dapat dimaknai bahwa apabila inovasi tim bertambah, maka kinerja tim diduga akan bertambah. Berdasarkan penjelasan tersebut, pada set pertama, penelitian ini memiliki hipotesa yaitu:

\section{Inovasi tim berpengaruh positif terhadap kinerja tim perajin gerabah di Kopinkra Satya Bhawana}

Budaya tim dapat menjadi salah satu faktor yang dapat mempengaruhi anggota tim untuk evaluasi diri dan memfasilitasi kinerja tim (Earley dan Mosakowski, 2000; Froehle, et,al, 2000). Budaya tim dipahami sebagai blok bangunan dalam desain tim yang memiliki batasan seperti norma-norma, 
nilai-nilai keyakinan, dan gaya perilaku anggotanya. Kekuatan utama di balik kemampuan tim untuk berubah adalah perilaku yang membantu tim melampaui kondisi saat ini dan berkonsentrasi untuk masa depan (Drach-Zahavy dan Somech, 2001). Gilson dan Shalley (2004) menemukan bahwa tim yang kreatif adalah tim beserta anggotanya menyadari bahwa mereka bekerja dengan ketergantungan tugas yang tinggi, membutuhkan tingkat kreativitas yang tinggi, tujuan bersama, pemecahan masalah secara partisipatif, dan iklim tim mendukung kreativitas anggota (Tesluk et. al, dalam McLean, 2005). Budaya tim dapat dijadikan sebagai refleksi sejauh mana pengaruh para pemimpin tim dalam memandang dan memahami tugas mereka di tempat kerja dengan menciptakan dan memelihara metafora dan mitos terhadap anggotanya (Alvesson, 2002).

\section{Budaya tim berpengaruh positif} terhadap kinerja tim perajin gerabah di Kopinkra Satya

\section{Bhawana}

Budaya tim diduga dapat memperkuat atau memperlemah hubungan inovasi tim terhadap kinerja tim perajin gerabah (Hu, et,al, 2009). Budaya tim dapat memungkinkan anggota tim berbagi, melakukan dialog yang konstruktif dan mengimplementasikan ide-ide mereka yang telah disepakati bersama. Sebab ide tidak disaring dan hanya melalui satu atau dua anggota (Leenders, et,al, 2003:). Pengukuran moderasi budaya tim dapat menghasilkan hasil yang bertentangan dan tidak meyakinkan (Chen et,al, 2007). Maka dari itu, penelitian ini menempatkan budaya tim sebagai variabel moderator pada hubungan inovasi tim terhadap kinerja tim perajin gerabah. Pada konteks ini, inovasi tim merangsang kinerja tim dan proses stimulasi akan dimoderatori oleh budaya tim dalam kasus Kopinkra Satya Bhawana di Kasongan. Maka dari itu, hipotesis selanjutnya adalah:

\section{Budaya tim memoderasi hubungan antara inovasi tim dan kinerja tim perajin gerabah di Kopinkra Satya Bhawana.}

\section{METODE}

Proses pengumpulan data dilaksanakan selama bulan Juli-Agustus 2014. Pembagian kuesioner ditargetkan 1.050 kuesioner untuk 192 tim perajin (100\% sampel). Kuesioner dibagikan secara stratified random sampling. Teknik tersebut dilakukan karena memperhatikan strata populasi perajin gerabah di Kopinkra Satya Bhawana yang terdiri dari tim perajin skala besar dan kecil. Setelah proses pengumpulan 
data, kuesioner dikembalikan berjumlah 1.003 kuesioner dari 178 tim (92\% sampel). Berdasarkan data yang terkumpul, jumlah anggota tiap tim bervariasi yaitu berkisar 3-16 orang. Item kuesioner dalam penelitian ini terdiri tiga skala diantaranya adalah pertama, 4 item skala inovasi tim dari Somech dan DrachZahavy (2001). Kedua, 15 item skala kinerja tim dari $\mathrm{Hu}$, et,al (2009). Ketiga,14 item skala budaya tim dari $\mathrm{Hu}$, et,al (2009) dengan indikator: dukungan tim, koordinasi tim dan kekompakan tim. Dalam perhitungan kuesioner, penelitian ini menggunakan skala likert $(5=$ Sangat setuju; 1=tidak setuju).

Pada penelitian ini, uji reabilitas data menggunakan koefisien korelasi intraclass (ICC). ICC digunakan untuk mengevaluasi apakah tindakan pada tingkat individu menunjukkan konsistensi yang cukup atau relatif dalam tim serta konsistensi dalam perbedaan antar kelompok untuk membenarkan agregasi. Sedangkan uji validitas menggunakan analisis faktor. Analisis faktor digunakan untuk mereduksi variabel pemoderasi yaitu dukungan tim, koordinasi tim dan kekompakan tim menjadi satu faktor yaitu budaya tim serta menghitung skor faktor yang akan digunakan dalam analisis regresi. Selanjutnya, uji regresi linear dilakukan untuk melihat pengaruh hubungan inovasi tim terhadap kinerja tim (H1). Sedangkan uji interaksi atau Moderate Regression Analysis (MRA) dilakukan untuk menganalisa hubungan inovasi tim terhadap kinerja tim dengan budaya tim sebagai variabel moderasi (H2 dan H3). Dengan demikian, uji interaksi dalam pengukuran penelitian ini dapat menguji tiga variabel yaitu inovasi tim, kinerja tim dan budaya tim.

\section{HASIL DAN PEMBAHASAN}

Berdasarkan hasil pengukuran, responden dalam penelitian ini banyak didominasi oleh laki-laki (62,2\%), berumur 27 tahun keatas $(86,6 \%)$, lulusan SMP $(38,2 \%)$, dan memiliki pengalaman bekerja lebih dari empat tahun berjumlah $87,5 \%$. Berdasarkan uji reliabilitas, nilai koefisien ICC pada 178 tim dengan pengukuran secara tunggal sebesar 0,305. Hal tersebut menunjukkan bahwa terdapat $30,5 \%$ variansi pada nilai inovasi tim, kinerja tim dan budaya tim merupakan variansi antar tim, sedangkan $69,5 \%$ sisanya merupakan variansi yang terdapat pada level individu. Nilai tersebut menunjukkan bahwa rasio ratarata kesepakatan agregasi tim di Kopinkra Satya Bhawana kurang memuaskan. Sedangkan hasil uji validitas, budaya tim menghasilkan indeks sebesar 3573.520 dengan derajat kebebasan 13 dan probabilitas 0,000. Hasil tersebut menjelaskan budaya tim 
berdistribusi normal dan data budaya tim yang telah dikumpulkan telah sesuai dengan sifat dan karakteristik populasi tim perajin gerabah di Kopinkra Satya Bhawana.

Berdasarkan pengukuran, $\mathrm{t}$ tabel pada df 1002 dengan signikansi 5\% adalah sebesar 1,960. Sedangkan t-hitung mencapai 25,290. Melihat hasil nilai thitung > t-tabel, maka H1 dapat diterima.Model persamaan regresi yang didapat adalah: $\mathbf{Y}=\mathbf{2 2 , 6 5 3}+\mathbf{2 , 1 3 7 X 1}$. Berdasarkan model tersebut, pengaruh inovasi tim terhadap kinerja tim sebesar 2,137 dengan tingkat signifikansi sebesar 0,000. Artinya, peningkatan kinerja tim satu satuan dibutuhkan inovasi tim sebesar 2,137 pada Kopinkra Satya Bhawana. Hasil tersebut menunjukkan bahwa inovasi tim berpengaruh positif pada kinerja tim sehinggahipotesa $\mathrm{H} 1$ diterima. Kondisi tersebut diperkuat dengan adanya pengrajin progresif yang memproduksi benda-benda hias berdasarkan pesanan konsumen. Raharjo (2008) menjelaskan bahwa terdapat perajin kerajinan keramik di Kasongan sebagai tokoh pembaharu dan berperan aktif dalam pengembangan material, teknologi produksi, dan desain seperti: Ngadiyo, Arjo Sidal, Sarijo, Punjul, dan Mukayat. Di samping itu, beberapa tim perajin kreatif mengembangkan bisnis gerabah berskala internasional seperti: sanggar Loro Blonyo, Tunas Asri Keramik, Yanto Ceramic, dan Timboel Keramik. Secara teoritis, hasil pengukuran tersebut menguatkan inovasi tim mempengaruhi kinerja tim yaitu dengan memberikan keunggulan kompetitif jangka panjang yang unggul pada tim (Fichman, 2001; Martins dan Terblanche, 2003; Wong dan Chin, 2007; Bate, 2010; Naranjo-Valencia, et,al, 2011), menawarkan kinerja pelayanan terbaru (Santos-Vijande, 2012), perubahan strategi dan inovasi layanan (Lightfoot dan Gebauer, 2011), perubahan lingkungan kerja yang menyenangkan dan mengarah pada peningkatan inovasi anggota (Huhtala dan Parzefall, 2007) serta berguna bagi perkembangan individu, tim, organisasi, atau masyarakat luas (Somech dan Drach-Zahavy, 2001; 2013).

Berdasarkan hasil uji interaksi, budaya tim berpengaruh positif terhadap kinerja tim. Nilait tabel pada df 1002 dengan signikansi 5\% adalah sebesar 1,960. Sedangkan t-hitung mencapai 2,006. Melihat hasil nilai t-hitung > ttabel, maka H2 dapat diterima. Di samping itu, pengungkapan budaya tim yang diproksikan dengan dukungan tim, koordinasi tim dan kekompakan tim berpengaruh positif pada kinerja timsebesar 1,685 dengan tingkat signifikansi sebesar 0,045 (signifikan). 
Kondisi tersebut sesuai dengan budaya tim sebagai dasar anggota tim untuk evaluasi diri dan memfasilitasi interaksi tim dan kinerja tim (Earley dan Mosakowski, 2000; Froehle, et. al, 2000). Namun, budaya tim tidak memiliki efek moderasi terhadap hubungan antara inovasi tim dan kinerja tim perajin gerabah di Kopinkra Satya Bhawana. Nilai koefisien moderasi (perkalian variabel inovasi tim dengan budaya tim) dalam mempengaruhi kinerja tim di Kopinkra Satya Bhawana hanya sebesar 0,001 dengan tingkat signifikansi sebesar 0,982 (artinya, signifikansi rendah karena lebih dari 0,05). Hasil tersebut menjelaskan bahwa pengaruh moderasi budaya tim tidak signifikan dalam mempengaruhi hubungan antara inovasi tim dan kinerja tim perajin gerabah di Kopinkra Satya Bhawana. Alasan mengapa hipotesa H3 tidak terbukti adalah proses koordinasi tim sebagai bagian dari budaya tim perajin gerabah di Kopinkra Satya Bhawana tidak berjalan seimbang.

Budaya tim di Kopinkra Satya Bhawana kurang memperhatikan esensi transfer kreatifitas produk dan peluang pasar antara tim skala besar terhadap tim skala kecil (tradisional). Dalam prakteknya, tim skala besarsering meminta bantuan kepada tim skala kecil untuk menyetor produk jadi sesuai pesanan tim skala besar agar selesai tepat waktu. Tim skala besar-modern cenderung lebih sering mendapatkan pesanan yang banyak (baik skala eksport/lokal) dibandingkan dengan tim skala kecil-tradisional. Tim skala kecil (tradisional) akhirnya banyak menghasilkan produk sesuai pesanan dari tim perajin skala besar sehingga cenderung monoton menghasilkan produk (hasil wawancara dengan Warjo, kepala UPT Kasihan tanggal 14 juni 2014). Kondisi tersebut mirip dengan studi Stark dan Longacre (1993) yang meneliti desa kerajinan keramik di Filifina Utara. Stark dan Longacre menjelaskan bahwa untuk menghindari kesulitan ekonomi yang diderita perajin, banyak jenis produk yang dihasilkan ternyata lebih bersifat pengulangan jenisjenis sebelumnya. Akibatnya, banyak produk tidak mengalami perkembangan signifikan, bersifat mengulang dan mentalitas yang tumbuh adalah mentalitas tukang yang merasa nyaman bila diatur oleh majikan.

Tidak munculnya inisiatif dan kreatifitas disertai ketidakmampuan mengelola menimbulkan ketakutan para pengrajin gerabah tradisional untuk membuat produk baru. Di samping itu, mereka merasa lebih nyaman bila mengikuti pesanan dan meneruskan produk yang sudah pasti laku. Sikap 
pasrah, narimo ing pandum terhadap kondisi kehidupan yang dialami merupakan konsep yang berkembang di kalangan masyarakat kecil, termasuk pengrajin gerabah tradisional di Kasongan. Pada kondisi tersebut, budaya tim yang diwakilkan oleh dukungan tim, kekompakan tim dan kerja sama tim belum cukup untuk mempengaruhi hubungan inovasi tim terhadap kinerja tim di Kopinkra Satya Bhawana. Hasil penelitian ini tidak mendukung penelitian $\mathrm{Hu}$, et,al (2009) yang meneliti hubungan manajemen berbagi pengetahuan dengan kinerja tim dengan budaya tim sebagai variabel moderasi pada tim karyawan hotel internasional di Taiwan. Hasil penelitian $\mathrm{Hu}$ et,al menunjukkan bahwa budaya tim yang diproksikan dengan kekompakan tim, koordinasi tim dan dukungan tim turut berperan dalam menjaga dan memoderasi hubungan antara manajemen berbagi pengetahuan dan kinerja layanan.

\section{SIMPULAN}

Penelitian ini bertujuan untuk menganalisa hubungan antara inovasi tim dan kinerja tim pada tim perajin gerabah serta menganalisa hubungan antara pengaruh budaya tim sebagai variabel moderasi pada hubungan inovasi tim dan kinerja tim di Kopinkra Satya Bhawana Kasongan, Bantul Yogyakarta.
Berdasarkan rumusan masalah penelitian yang diajukan dan pembahasan, maka dapat ditarik dua kesimpulan dari penelitian ini, diantaranya meliputi:

Pertama, inovasi tim berpengaruh positif dan signifikan terhadap kinerja tim perajin gerabah Kopinkra Satya Bhawana. Berdasarkan hasil, pengaruh inovasi tim terhadap kinerja tim sebesar 2,137 dengan tingkat signifikan mencapai 0,000. Artinya, peningkatan kinerja tim satu satuan dibutuhkan inovasi tim sebesar 2,137 pada Kopinkra Satya Bhawana. Kondisi tersebut disebabkan oleh adanya pengrajin progresif yang menghasilkan produknya mengikuti selera pasar yaitu konsumen yang mempunyai keunggulan modal materi, simbolik dan budaya.

Kedua, budaya tim (kekompakan tim, koordinasi tim dan dukungan tim) tidak memberikan efek moderasi yang memberikan pelemahan atau penguatan pada hubungan antara inovasi tim dan kinerja tim. Kinerja tim perajin gerabah di Kopinkra Satya Bhawana tetap baik. Berdasarkan hasil, nilai koefisien moderasi (perkalian variabel inovasi tim dengan budaya tim) dalam mempengaruhi kinerja tim di Kopinkra Satya Bhawana sebesar 0,001 dengan tingkat signifikansi $0,982 \quad$ (tidak signifikan karena lebih dari 0,05). Penyebabnya adalah proses koordinasi 
sebagai bagian dari budaya tim di Kopinkra Satya Bhawana tidak berjalan seimbang. Koordinasi tim kurang memperhatikan esensi transfer kreatifitas produk dan peluang pasar. Kondisi ini berdampak pada kurangnya perkembangan optimalisasi potensi baru dari tim perajin gerabah skala kecil. Sebab pada kondisi tertentu, tim skala kecil hanya sekedar mengerjakan sesuai pesanan dari tim perajin skala besar dan cenderung monoton dalam menghasilkan produknya.

Beberapa keterbatasan penelitian ini yang perlu menjadi bahan pengembangan pada penelitian selanjutnya adalah sebagai berikut:

1. Secara praktik, diperlukan kegiatan transfer kreatifitas produk dan peluang pasar dalam koordinasi tim sebagai bagian dari budaya tim di Kopinkra Satya Bhawana. Kegiatan ini penting dalam optimalisasi potensi baru dari tim perajin gerabah skala kecil.

2. Penelitian ini hanya menggunakan sampel tim perajin gerabah. Penelitian selanjutnya disarankan untuk menambah jumlah sampel dengan memperluas jenis koperasi UMKM lainnya agar hasil penelitian lebih dapat digeneralisasi.
3. Penelitian selanjutnya dapat menyertakan aspek pengukuran kualitatif seperti in depth interview sehingga lebih mendalam.

4. Penelitian ini menggunakan variabel budaya tim yang diproksikan dengan dukungan tim, koordinasi tim dan kekompakan tim. Penelitian selanjutnya dapat menambah proksi budaya tim lainnya seperti pembelajaran tim, altruisme, simbiosis dan reputasi. Sebab budaya tim memiliki keanekaragaman karakteristik dan pengaruh yang berbeda terhadap tim atau organisasi.

\section{DAFTAR PUSTAKA}

Ahuja, Jaya, Study, 2010, A Study of Virtuality Impact on Team Performance, The IUP Journal of Management Research, Vol. IX, No. 5, pp 27-56

Amabile, Teresa M.; Regina Conti; Heather Coon; Jeffrey Lazenby; Michael Herron, Assessing the Work Environment for Creativity, The Academy of Management Journal. pp.1154-1184

Bain, P. G., Mann, L, \& Pirola-Merlo, A. (2001). The Innovation Imperative: The Relationships Between Team Climate, Innovation, And Performance In Research And Development Teams. Small Group Research, 32, 55-73.

Baker, William E. dan James M. Sinkula, 2002, Market Orientation, Learning Orientation And Product Innovation: 
Delving Into The Organization's Black Box, Journal Of MarketFocused Management, pp 5-23

Bandow, Diane, 2001, Time To Create Sound Teamwork, The Journal For Quality And Participation, 24, 2; Pg. 4

Baruch, Yehuda, Chieh-Peng Lin, 2012, All for one, one for all: Comopetition and virtual team performance, Technological Forecasting and Social Change, Pages 1155-1168

Bate, J. D. 2010. How To Explore For Innovation On Your Organization's Strategic Frontier, Strategy and Leadership, 38, 32-36

Chansler, Phillip A, et,al, 2003, Selfmanaging work teams: An empirical study of Group cohesiveness In "Natural Work Groups" at a Harleydavidson motor company plant, Small group research, vol. 34 no. 1,

Chen, G., Kirkman, B. L., Kanfer, R., \& Allen, D. (2007). A multilevel study of leadership, empowerment, and performance in teams. Journal of Applied Psychology, 92(2), 331-346

Chermack, et,al, 2010, Two Strategies for Leveraging Teams Toward Organizational Effectiveness: Scenario Planning and Organizational Ambidexterity, Advances in Developing Human Resources 12(1) $137-156$

Costa, Ana Cristina, 2003, Work Team Trust And Effectiveness, Personnel Review; 32, 5; pg. 605

Crossan, Mary M. and Marina Apaydin, 2010, A Multi-Dimensional Framework of Organizational Innovation: A Systematic Review of the Literature, Journal of Management Studies vol 47:pp 11541180

Davies, H. T. O. R. Mannion, R. Jacobs, A. E. Powell and M. N. Marshall,
Exploring the Relationship between Senior Management Team Culture and hospital performance, Med Care Res Rev 2007 pp 64: 46

Doolen, T.L., M.E. Hacker, E.M. Van Aken, Impact of organizational context on work team effectiveness: a study of production team, IEEE Trans. Eng. Manag. 50 (2003) 285296.

Drach-Zahavy, Anat and Anit Somech, 2001, Understanding Team Innovation: The Role of Team Processes and Structures, Group Dynamics: Theory, Research, and Practice, Vol.5, No.2, pp 111-123

Earley, P. C., \& Mosakowski, E. (2000). Creating hybrid team cultures: an empirical test of transnational team functioning, Academy of Management Journal, 43(1), pp 2649

Fichman, Robert G, 2001, The role of aggregation in the measurement of it-related Organizational innovation, Management Information Systems Quarterly, 2001, Volume 24, Issue 4, pp 427-455

Fransen, J., Kirschner, P.A.\& Erkens, G. (2011). Mediating team effectiveness in the context of Collaborative learning: The importance of team and task awareness, Computers in Human Behavior, 27(3), pp 11031113.

Franco-Santos, Monica, Kennerley, MikeMicheli, PietroMartinez, VeronicaMason, SteveMarr, BernardGray, DinaNeely, Andy, 2007, Towards A Definition Of A Business Performance Measurement System, International Journal of operation and production management, vol 27 (8): pp 784-801

Froehle, Craig M, Aleda V.Roth, Richard B.Chase, dan Christopher AVoss, 2000, Antecedents of New Service 
Development Effectiveness: An Exploratory Examination of Strategic Operations Choices, Student Paper:pp 1-30

García-Herrero, Susana, M.A. Mariscal, J.M. Gutiérrez, Antonio Toca-Otero, Bayesian network analysis of safety culture and organizational culture in a nuclear power plant, Safety Science 53 (2013) pp 82-95

Hervas-Oliver, Jose-Luis, Ian Jackson and Philip R. Tomlinson (2011) "May the ovens never grow cold": regional resilience and industrial policy in the North Staffordshire ceramics industrial district - with lessons from Sassoulo and Castellon', Policy Studies, 32:4, 377395.

Hogan, Suellen J dan Leonard V. Coote, Organizational Culture, Innovation, And Performance: A Test Of Schein's Model, Journal of Business Research 67 (2014) pp 1609-1621

$\mathrm{Hu}$, Meng-Lei Monica, Jeou-Shyan Horng, Yu-Hua Christine Sun, 2009, Hospitality Teams: Knowledge Sharing And Service Innovation Performance, Tourism Management vol 30, pp 41-50

Huhtala, Hannele dan Parzefall, MarjoRiitta (2007). Review of Employee Well-Being And Innovativeness: An Opportunity For Mutual Benefit, A Creativity and Innovation Management 16(3), pp. 299-306

Hulsheger, Ute R, et,al, 2009, TeamLevel Predictors of Innovation at Work: A Comprehensive MetaAnalysis Spanning Three Decades of Research, Journal of Applied Psychology, Vol. 94, No. 5, pp 1128 $-1145$

Jackson, Ian and Philip R. Tomlinson (2009) 'The role of cooperation in a creative industry: the case of $U K$ studio pottery', International Review of Applied Economics, 23, 6: 691708.

Keller, R. T. (2001). Cross-functional project groups in research and new product development: Diversity, communications, job stress, and outcomes. Academy of Management Journal, 44, pp 547-555

Kozlowski, S., \& Bell, B. (2008). Work group learning: Understanding, improving and assessing how groups learn in organizations (pp. 15--44). New York, NY: Taylor \& Francis Group/ Lawrence Erlbaum Associates.

Leenders, R., Th, A. J., van Engelen, J. M. L., \& Kratzer, J. (2003). Virtuality, communication, and new product team creativity: a social network perspective. Journal of Engineering and Technology Management, 20(1-2), 69-92

Lightfoot, Howard W. dan Heiko Gebauer, 2011, Exploring The Alignment Between Service Strategy And Service Innovation, Journal of Service Management, Vol. 22 No. 5, pp. $664-683$

Matthing, J., Sanden, B., \& Edvardsson, B. (2004). New service development:Learning from and with customers. International Journal of service Industry Management, 15(5), 479-498

McLean, Laird D. 2005, Organizational Culture's Influence on Creativity and Innovation: A Review of the Literature and Implications for Human Resource Development, Advances in Developing Human Resources vol 7: pp 226

Naranjo-Valencia. J. C., Jime'nezJime'nez, D., dan Sanz-Valle, R. (2011), Innovation or imitation? The role of organizational culture, Management Decision, 49(1), pp 5572 
Pryor, mildred golden, et,al, 2009, Teaming As A Strategic And Tactical Tool: An Analysis With Recommendations, International journal of management vol. 26 no. 2 , pp 320

Pryor, mildred golden, et,al, 2009, Teaming As A Strategic And Tactical Tool: An Analysis With Recommendations, International journal of management vol. 26 no. 2 pp 320

Reiter-Palman, Ben Wigert, and Triparna de Vreede, 2012, Team Creativity and Innovation: The Effect of Group Composition, Social Processes, and Cognition, Handbook of Organizational Creativity

Rosing, K., Frese, M., \& Bausch, A. (2011). Explaining The Heterogeneity Between The Leadership-Innovation Relationship: Ambidextrous Leadership. The Leadership Quarterly, 22, pp 956974.

Santos-Vijande, María Leticia, José Ángel López-Sánchez And Celina González-Mieres, 2012, Organizational Learning, Innovation, And Performance In KIBS, Journal of Management \& Organization, vol 18(6), pp 870-904

Somech, Anit, Anat Drach-Zahavy, Translating Team Creativity to Innovation Implementation: The Role of Team Composition and Climate for Innovation, Journal of Management Vol. 39 No. 3, March 2013, pp 684-708

Stark, Miriam T. Dan William A. Longacre, 1993, Kalinga ceramics and new technologies: Social and cultural contexts of ceramic change, Ceramics \& Civilization Vol. VI, The American Ceramic Society Westreville, $\mathrm{OH}$
Stashevsky, Shmuel and Meni Koslowsky, 2006, Leadership team cohesiveness and team performance, International Journal of Manpower, Vol. 27 No. 1, pp. 63-74

Tomlinson, Philip R. and Ian Jackson (2011) 'Cooperative Ties and the Impact of External Factors upon Innovation in an Industrial District: Some Insights from the North Staffordshire Table and Giftware Sector', Regional Studies, 2013 Vol. 47, No. 4, 580-596

Wilson, J.M, Goodman, P.S. and Cronin, M.A. (2007), Group Learning, Academy of Management Review, Vol. 32, pp. 1041-1059

Wong, S., \& Chin, K, 2007. Organizational Innovation Management: An Organization-Wide Perspective, Industrial Management and Data Systems, 107(9), pp 12901315

Zaccaro, Stephen j., Andrea L. Rittman, Michelle A. Marks, 2001, Team Leadership, The Leadership Quarterly 12 (2001) pp 451-483

Zaccaro, Stephen J. and Richard Klimoski, 2002, The Interface of Leadership and Team Processes, journal Group \& Organization Management Vol 27: pp 4-11

Zsuzsanna, Turóczy, Liviu Marian, Multiple regression analysis of performance indicators in the ceramic industry, Procedia Economics and Finance 3 ( 2012 ) $509-514$

Zsuzsanna, Turóczy, Liviu Marian, Illés Sándor, The analysis of the ceramic ector in Romania's Center Development Region, Procedia Economics and Finance 15 ( 2014 ) $1209-12$ 